\title{
Association between Handwashing Behavior and Infectious Diseases among Low-Income Community Children in Urban New Delhi, India: A Cross-Sectional Study
}

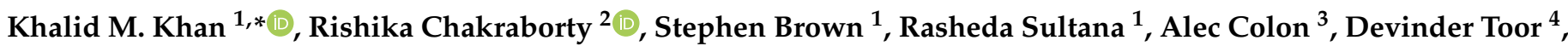 \\ Pooja Upreti ${ }^{4}$ and Banalata Sen ${ }^{5}$ \\ 1 Department of Population Health, College of Health Sciences, Sam Houston State University, \\ Huntsville, TX 77341, USA; sbrown@shsu.edu (S.B.); mxs218@shsu.edu (R.S.) \\ 2 Department of Environmental and Occupational Health, School of Public Health, \\ Indiana University Bloomington, Bloomington, IN 47405, USA; rchakra@iu.edu \\ 3 Massachusetts General Hospital Cancer Center, Boston, MA 02114, USA; acolon344@gmail.com \\ 4 Amity Institute of Virology and Immunology, Amity University Uttar Pradesh, Noida 201313, India; \\ dtoor@amity.edu (D.T.); poojauprety232@gmail.com (P.U.) \\ 5 Sustainable Environment and Ecological Development Society (SEEDS), New Delhi 110022, India; \\ bonosen@gmail.com \\ * Correspondence: kxk051@shsu.edu
}

check for

updates

Citation: Khan, K.M.; Chakraborty,

R.; Brown, S.; Sultana, R.; Colon, A.;

Toor, D.; Upreti, P.; Sen, B.

Association between Handwashing

Behavior and Infectious Diseases

among Low-Income Community

Children in Urban New Delhi, India:

A Cross-Sectional Study. Int. J.

Environ. Res. Public Health 2021, 18,

12535. https://doi.org/10.3390/

ijerph182312535

Academic Editor: Alessandra

Casuccio

Received: 1 October 2021

Accepted: 23 November 2021

Published: 28 November 2021

Publisher's Note: MDPI stays neutral with regard to jurisdictional claims in published maps and institutional affiliations.

Copyright: (c) 2021 by the authors. Licensee MDPI, Basel, Switzerland. This article is an open access article distributed under the terms and conditions of the Creative Commons Attribution (CC BY) license (https:// creativecommons.org/licenses/by/ $4.0 /)$

\begin{abstract}
Diarrheal diseases and respiratory infections (RI) are two leading causes of childhood mortality in low and middle-income countries. Effective handwashing at critical time-points may mitigate these diseases. However, there is a lack of published data investigating this association in school-aged children in India. This study is part of a larger prospective handwashing intervention study in a low-income community in New Delhi, India examining the associations between handwashing behavior and diarrhea and RI in schoolchildren. This current study reports the findings of the baseline survey administered to 272 mother-child dyads. Children aged 8-12 years, and their mothers, were recruited from six schools. A baseline questionnaire was used to collect sociodemographic data, handwash behavior, and mother-reported recent diarrhea and RI incidence among the children. Handwashing before and after preparing food, after defecation, and after cleaning dishes significantly reduced the odds of diarrhea by over $70 \%$, and of RI by over $56 \%$. Using a clean cloth after handwashing lowered odds of diarrhea and RI by $72 \%$ and $63 \%$ respectively. Around $60 \%$ of the participants believed that handwashing could prevent diarrhea and RI in their children. There was a low prevalence of handwashing at critical time-points and a poor perception regarding handwashing benefits. To improve handwashing behavior, hygiene promotion programs need to understand what motivates and hinders handwashing in vulnerable populations.
\end{abstract}

Keywords: diarrhea; handwashing critical time points; respiratory infections; schoolchildren

\section{Introduction}

Diarrhea and respiratory infections (RI) continue to be leading causes of childhood morbidity and mortality in developing countries [1]. Diarrheal diseases and RI account for about 1.3 and 2.6 million annual deaths respectively [2]. However, the burden of these diseases is disproportionately higher in low and middle-income countries (LMICs), including India [3]. The World Health Organization (WHO) has estimated that diarrhea and RI account for approximately $30 \%$ and 18\% respectively, of the global burden of disability adjusted life years for the people of India [4]. There are multiple etiological agents for infectious diarrhea and RI. Diarrhea is commonly caused by bacteria such as Escherichia coli and Vibrio cholerae [5]; by viruses such as rotavirus and adenovirus and parasites such as Giardia [6]. The predominant bacterial and viral agents causing RI include Streptococcus pneumoniae, Klebsiella pneumoniae, rhinoviruses and influenza viruses [7-9]. 
Children are most vulnerable to these infectious diseases when they lack access to safe water and sanitation, have poor hygiene behavior in and outside their homes, and experience nutritional deficiencies [10]. Children attending elementary school are especially vulnerable because these diseases also impede academic and physical development, leading to impaired cognitive performance [11] and stunting growth [12]. Disruptions during childhood development often lead to poor quality of life in adulthood [13,14].

Improved hygiene practices are considered among the most cost-effective social interventions for reducing the burden of diarrheal diseases and RI. Handwashing is the most prominent and affordable hygiene practice for low-income populations [15-17]. Handwashing with soap can reduce the risk of diarrhea by $47 \%$ [18] and the risk of RI by $24 \%$ [19]. Despite extensive governmental and non-governmental public health educational efforts to promote hygiene practices, the rate of compliance is still critically low in LMICs, including in India. Globally, only 19\% of the population wash hands after fecal contact [20] while according to one study, only 2\% handwash in India after fecal contact [21]. Because of poor handwashing behavior, incidence of infectious diseases remains high in India, costing an estimated USD 23 billion every year [22]. By targeting sensitive groups in low-income populations, particularly children, public health practitioners can not only reduce morbidity and mortality from RI and diarrhea, but also improve overall economic wellbeing.

Community or school-based handwashing interventions have been shown to raise hygiene awareness, lower risk of infectious diseases, and reduce school absenteeism in students [23-25]. These children, in turn, can become influential in encouraging family members to adopt better hygiene practices [26]. Most published handwashing hygiene interventions have targeted children younger than 5 years of age [27-29]. However, risk for fecal contact is higher for children in school. Older children demonstrate high frequency hand-to-mouth transfer as they come into contact with fecal matter while playing on the school grounds and sharing crowded washrooms that often lack proper handwashing facilities. Consequently, school children are at high risk of developing diarrheal diseases and RI [30]. Although several studies have reported the impact of poor handwashing on infectious diseases among children in India, the protective effects of hygiene practices (i.e., behavior and timing of handwash at home or school) has not been explored. Understanding this may be important because handwashing behavior of the mothers and children could reduce diarrhea and RI in children [31,32]. In this study, we examined the associations between handwashing behavior and diarrhea and respiratory infections in children between 8 to 12 years of age. We present the findings of a cross-sectional study using the baseline data from a prospective educational intervention on school children, living in low-income urban slum communities in East Delhi, India.

\section{Materials and Methods}

\subsection{Study Design and Setting}

This current study utilizes the baseline data of a prospective handwashing behavior change intervention study conducted in East Delhi, which began in August 2018 and is currently ongoing. The intervention study is a collaborative project involving the faculty, staff, and students of Indiana University Bloomington (IUB) in the United States and three Indian institutions, Ambedkar University Delhi (AUD), Amity University Uttar Pradesh (AUUP) and Sustainable Environment and Ecological Development Society (SEEDS).

SEEDS has been working with several public (government-funded) elementary schools (locally known as primary schools) located in low-income communities in East Delhi. Most of the children attending these schools belong to migrant families who relocated from rural communities across India to East Delhi for work. From a list of 50 primary schools located in East Delhi, six schools were randomly selected for the hand washing behavior change intervention project. Mother-child dyads were selected from these six schools. The present study reports the findings of baseline surveys administered to the mother-child dyads before the start of the behavior change intervention. Since this study reports results from only the baseline data of the project, we present our findings for all participants from the 
six schools together. Ethical approval for this study was obtained from the Institutional Review Boards at both IUB and AUUP.

\subsection{Sample Size and Participant Recruitment}

Third to sixth grade teachers, from the six selected schools, identified eligible child participants based on our inclusion criteria. To be included, child participants had to be between 8-12 years of age, be students attending third to fifth grades, have no physical or mental disability, live in urban slums, and have a physically active mother living in the same house with the child. If more than one child in a household was eligible, only one was selected. From an initial list of 482 participants from the same number of households who met the inclusion criteria, we randomly selected 50 potential child participants from each school and reached out to their mothers for informed verbal consent. Although our initial target was to recruit fifty children per school thus achieving a sample size of 300 for the study, 28 participants were unable, or unwilling, to take part in the study, giving a response rate of $90.7 \%$. Among these 28 excluded participants, mothers of 20 were not available when our field staff reached out to them since they moved to another city at the time of recruitment, whereas 8 children were found to have chronic illness not allowing them to attend schools regularly. Therefore, our final sample included 272 randomly recruited mother-child dyads from six schools. We obtained verbal informed consent from mothers and child assent before initiating any data collection activity.

\subsection{Questionnaire Survey}

The Principal Investigator from IUB, USA and the local Co-Investigators trained the SEEDS research assistants (RAs) to conduct face-to-face interviews with the mother-child dyads. The RAs used a structured questionnaire to collect data from the mother-child dyads regarding socio-demographic characteristics, hand-washing practices, beliefs, behaviors, and diarrheal disease and RI incidence among children. Each mother responded to all the questions in presence of the child participant, via a face-to-face interview with our field staff. Standing height of all children was assessed using a measuring tape to the nearest cm (Stanley 33-725 25-Feet FatMax Tape, Stanley Tools, New Britain, CT, USA) and child weight was measured to the nearest kilogram using a calibrated digital weighing scale (Hoffen HO-18 Digital Electronic Weighing Scale, ACE Incorporation, India). The height and weight measurements were used to compute body mass index (BMI).

\subsection{Handwash Behaviors and Practices}

Mothers and children self-reported their usual handwashing time-points, behaviors, and facilities at home and in school. Each handwashing behavior and occasion was recorded as binary variables with "yes" or "no" answers. For example, "used liquid soap to wash hands" and "washed hands before eating" both had answer options "yes" or "no".

\subsection{Health Outcomes}

The two child health outcomes assessed in this study were diarrhea and RI in the past 12 months, as reported by the mothers. Diarrhea was measured by the question, "Did your child get any diarrheal diseases in the past 12 months?" and RI with "Did your child get any respiratory illnesses in the past 12 months?" with "yes" or "no" answer options. The mothers were also asked to elaborate what type of diarrhea or RI the child suffered in the past 12 months. Diarrhea was defined as passage of 3 or more loose or liquid stools per day or more frequently than normal for the individual [33]. RI was defined as pneumonia, cough, fever, chest pain and shortness of breath, cold, inflammation of the airways or any other symptoms of respiratory illnesses [34].

\subsection{Statistical Analysis}

Statistical analysis was performed using $\mathrm{R}$ statistical programming software v3.6.0. Sociodemographic characteristics of the mother-child dyads are presented as mean \pm 
standard deviation for continuous variables and number (\%) for categorical variables. Bivariate analyses were performed using Chi-square tests or Fisher's tests. Separate unadjusted and adjusted logistic regression models were performed to investigate the association of each major explanatory variable such as individual handwashing behavior and critical handwashing time point with the health outcomes of diarrheal and RI incidence. Along with a major explanatory variable, we also considered child age, BMI, mother's education, and monthly household income as potential covariates in each model. Therefore, five explanatory variables were used in each model. To detect potential multicollinearity in our regression models, we calculated the variance inflation factor (VIF) for each model. We found VIF was less than 1.5 for all models, indicating low correlation among our predictor variables. We defined statistical significance as $p<0.05$ tests for the hypotheses were two-sided.

\section{Results}

\subsection{Sociodemographic Characteristics}

The sociodemographic characteristics of all child participants are described in Table 1. On average, children were 9 years old, and their mothers were 32 years old. Average child BMI was nearly $15 \mathrm{~kg} / \mathrm{m}^{2}$, and was within normal range according to WHO reference growth charts [35]. Over half (58.8\%) of the child participants were male. About half $(53.7 \%)$ of the maternal participants had received no schooling, while nearly $70 \%$ of the fathers had received some education (primary and/or secondary and above). Three-fifths $(60 \%)$ of the mothers were unemployed while nearly all $(97.2 \%)$ of the fathers had some form of employment. Two-thirds (67\%) of the households had five or fewer household members, and majority $(80 \%)$ rented their homes. About $11 \%$ of the households had a monthly income of less than or equal to 6000 INR. Diarrhea incidence in the past year was reported in $23.5 \%$ of the child participants while RI incidence in the past year was reported in $37.5 \%$ of the child participants. Diarrhea and RI incidence was similar between girls and boys $(p>0.05)$.

Table 1. Sociodemographic characteristics of the participants $(N=272)$.

\begin{tabular}{cc}
\hline Characteristic & $\begin{array}{c}\text { Child Participants } \\
(\mathbf{N}=\mathbf{2 7 2}) \\
\text { (Mean } \pm \text { S.D) }\end{array}$ \\
\hline Child's Age & $9.08 \pm 1.17$ \\
Mother's Age & $31.81 \pm 4.45$ \\
Child's BMI & $14.99 \pm 2.99$ \\
\hline Sex & $\mathrm{n}(\%)$ \\
Female & $112(41.2)$ \\
Male & $160(58.8)$ \\
\hline Educational status of mother & $146(53.7)$ \\
Primary & $93(34.2)$ \\
Secondary and above & $33(12.1)$ \\
\hline Educational status of father & $81(29.8)$ \\
No school & $94(34.6)$ \\
Primary & $97(35.6)$ \\
\hline Secondary and above &
\end{tabular}


Table 1. Cont.

\begin{tabular}{|c|c|}
\hline Characteristic & $\begin{array}{c}\text { Child Participants } \\
(N=272) \\
(\text { Mean } \pm \text { S.D) }\end{array}$ \\
\hline \multicolumn{2}{|l|}{ Employment status of mother } \\
\hline Employed & $106(39.0)$ \\
\hline Unemployed & $166(61.0)$ \\
\hline \multicolumn{2}{|l|}{ Employment status of father } \\
\hline Employed & $264(97.1)$ \\
\hline Unemployed & $8(2.9)$ \\
\hline \multicolumn{2}{|l|}{ No. of people in a household } \\
\hline$\leq 5$ & $183(67.3)$ \\
\hline$>5$ & $89(32.7)$ \\
\hline \multicolumn{2}{|l|}{$\begin{array}{l}\text { Monthly household income } \\
\text { (INR) }\end{array}$} \\
\hline$<2000-6000$ & $29(10.7)$ \\
\hline $6001-10,000$ & $119(43.7)$ \\
\hline$>10,000$ & $124(45.6)$ \\
\hline \multicolumn{2}{|l|}{ Home ownership } \\
\hline Own home & $52(19.1)$ \\
\hline Rental home & $220(80.9)$ \\
\hline Diarrheal disease incidence & $64(23.5)$ \\
\hline Respiratory illness incidence & $102(37.5)$ \\
\hline
\end{tabular}

\subsection{Handwashing Behaviors and Infectious Disease Outcomes}

Handwashing behavior, and its association with diarrheal disease and RI outcomes in children, determined by multivariate logistic regression models, are outlined in Tables 2 and 3 respectively. Handwashing was practiced by both mother and children in $80.4 \%$ of the households. Use of bar or liquid soap was not associated with both of our infectious disease outcomes. As far as handwashing facilities were concerned, having water in a tub with a mug outside the house significantly increased the odds of getting diarrheal disease by 3.14 times. Such unexpected results were not observed for RI. Wiping hands with a clean cloth was significantly protective against both infectious disease outcomes. The strongest barrier to handwashing was forgetting to wash hands at critical periods, reported by $12.9 \%$ of the participants. This significantly increased the odds of getting diarrhea by 3.91 times. Forgetting to wash hands was also associated with higher odds of RI in the unadjusted analyses, but was attenuated after adjusting for covariates. Most handwashing behaviors were not significantly different between girls and boys. However, more girls $(89.3 \%)$ reported using a bar soap than boys $(78.1 \%)$; while $23.2 \%$ of the girls identified "being tired of handwashing" as a potential barrier, as opposed to only $13 \%$ of the boys $(p<0.05)$. The frequency of handwashing behavior by participants who reported incidence of diarrheal disease ranged from $1.6 \%$ to $85.9 \%$, across a wide range of behaviors described in Table 2. For those who reported RI incidence, frequency of handwashing behavior ranged from $1.9 \%$ to $86.3 \%$ for the different behaviors (Table 3 ). 
Table 2. Unadjusted and adjusted odds ratios for association between handwashing behaviors at home and diarrheal disease outcome.

\begin{tabular}{|c|c|c|c|c|c|c|c|c|c|}
\hline Behaviors & $\begin{array}{c}\text { Diarrhea } \\
\text { IncidenceN }=64\end{array}$ & $\begin{array}{l}\text { No Diarrhea } \\
\text { Incidence } \\
N=207\end{array}$ & $p$ Value ${ }^{\#}$ & $\begin{array}{c}\text { OR for } \\
\text { Diarrheal } \\
\text { Disease }\end{array}$ & $95 \% \mathrm{CI}$ & $p$ Value & $\begin{array}{l}\mathrm{OR}^{\mathrm{a}} \text { for Diarrheal } \\
\text { Disease }\end{array}$ & $95 \%$ CI & $p$ Value \\
\hline \multicolumn{10}{|c|}{ Soap type } \\
\hline Bar & $55(85.9)$ & $170(82.1)$ & 0.48 & 1.33 & $0.63,3.09$ & 0.48 & 1.69 & $0.75,4.20$ & 0.22 \\
\hline \multicolumn{10}{|c|}{ Handwashing facility } \\
\hline Basin and tap inside toilet & $5(7.8)$ & $39(18.8)$ & 0.04 & 0.37 & $0.12,0.89$ & 0.04 & 0.39 & $0.13,0.99$ & 0.07 \\
\hline Basin and tap outside toilet & $13(20.3)$ & $74(35.7)$ & 0.02 & 0.46 & $0.23,0.87$ & 0.03 & 0.48 & $0.23,0.95$ & 0.04 \\
\hline Water in tub with mug outside & $16(25.0)$ & $20(9.7)$ & 0.002 & 3.12 & $1.49,6.46$ & $<0.01$ & 3.14 & $1.43,6.86$ & $<0.01$ \\
\hline \multicolumn{10}{|c|}{ Hand drying method } \\
\hline Clean cloth & $9(14.1)$ & $89(42.9)$ & $<0.001$ & 0.22 & $0.09,0.44$ & $<0.001$ & 0.28 & $0.12,0.59$ & 0.001 \\
\hline Multi-purpose rag & $45(70.3)$ & $97(46.9)$ & 0.001 & 2.68 & $1.49,4.99$ & $<0.01$ & 1.82 & $0.96,3.55$ & 0.07 \\
\hline Air dry & $3(4.7)$ & $27(13.0)$ & 0.06 & 0.33 & $0.08,0.97$ & 0.08 & 0.48 & $0.11,1.52$ & 0.26 \\
\hline Wipe on clothes & $10(15.6)$ & $48(23.2)$ & 0.20 & 0.61 & $0.28,1.25$ & 0.20 & 0.72 & $0.31,1.51$ & 0.40 \\
\hline \multicolumn{10}{|c|}{ Barriers to handwashing } \\
\hline Too busy & $50(78.1)$ & $177(85.5)$ & 0.16 & 0.61 & $0.30,1.26$ & 0.16 & 0.69 & $0.34,1.50$ & 0.34 \\
\hline No soap & $1(1.6)$ & $2(0.9)$ & 0.56 & 1.63 & $0.07,17.26$ & 0.69 & 1.18 & $0.05,13.35$ & 0.89 \\
\hline Forgot & $18(28.1)$ & $17(8.2)$ & $<0.001$ & 4.35 & $2.08,9.17$ & $<0.001$ & 3.91 & $1.75,8.83$ & $<0.001$ \\
\hline
\end{tabular}

\# Results from Chi-square test/Fisher test, ${ }^{\text {a }}$ adjusted for child age, BMI, mothers education, monthly household income. 
Table 3. Unadjusted and adjusted odds ratios for association between handwashing behaviors at home and respiratory illness outcome.

\begin{tabular}{|c|c|c|c|c|c|c|c|c|c|}
\hline Behaviors & $\begin{array}{l}\text { Respiratory Illness } \\
\text { Incidence } \\
N=102\end{array}$ & $\begin{array}{c}\text { No Respiratory } \\
\text { Illness } \\
N=168\end{array}$ & $p$ Value $\#$ & $\begin{array}{l}\text { OR for } \\
\text { Respiratory } \\
\text { Illness }\end{array}$ & $95 \% \mathrm{CI}$ & $p$ Value & $\begin{array}{c}\text { OR }^{a} \text { for } \\
\text { Respiratory Illness }\end{array}$ & $95 \% \mathrm{CI}$ & $p$ Value \\
\hline \multicolumn{10}{|c|}{ Soap type } \\
\hline Bar & $88(86.3)$ & $137(81.5)$ & 0.31 & 1.42 & $0.73,2.89$ & 0.31 & 1.71 & $0.84,3.65$ & 0.15 \\
\hline \multicolumn{10}{|c|}{ Handwashing facility } \\
\hline Basin and tap inside toilet & $18(17.6)$ & $26(15.5)$ & 0.64 & 1.17 & $0.60,2.25$ & 0.64 & 1.40 & $0.69,2.79$ & 0.34 \\
\hline Basin and tap outside toilet & $33(32.4)$ & $54(32.1)$ & 0.97 & 1.01 & $0.59,1.70$ & 0.97 & 1.06 & $0.60,1.85$ & 0.84 \\
\hline Water in tub with mug outside & $15(14.7)$ & $21(12.5)$ & 0.61 & 1.21 & $0.58,2.45$ & 0.61 & 1.04 & $0.49,2.20$ & 0.91 \\
\hline \multicolumn{10}{|c|}{ Hand drying method } \\
\hline Clean cloth & $21(20.6)$ & $77(45.8)$ & $<0.001$ & 0.31 & $0.17,0.53$ & $<0.001$ & 0.37 & $0.19,0.67$ & 0.001 \\
\hline Multi-purpose rag & $64(62.7)$ & $77(45.8)$ & $<0.01$ & 1.99 & $1.21,3.31$ & $<0.01$ & 1.71 & $0.98,2.99$ & 0.06 \\
\hline Air dry & $14(13.7)$ & $16(9.5)$ & 0.29 & 1.51 & $0.70,3.25$ & 0.29 & 1.60 & $0.68,3.76$ & 0.28 \\
\hline Wipe on clothes & $18(17.6)$ & $40(23.8)$ & 0.23 & 0.69 & $0.36,1.26$ & 0.24 & 0.75 & $0.38,1.41$ & 0.38 \\
\hline \multicolumn{10}{|c|}{ Barriers to handwashing } \\
\hline Too busy & $77(75.5)$ & $150(89.3)$ & 0.002 & 0.37 & $0.19,0.71$ & $<0.01$ & 0.42 & $0.21,0.82$ & 0.01 \\
\hline No soap & $2(1.9)$ & $1(0.6)$ & 0.55 & 3.34 & $0.32,72.41$ & 0.33 & 2.05 & $0.19,45.55$ & 0.57 \\
\hline
\end{tabular}

${ }^{\#}$ Results from Chi-square test/Fisher test, ${ }^{\text {a }}$ adjusted for child age, BMI, mothers education, monthly household income. 


\subsection{Timing of Handwash Activities and Infectious Disease Outcomes}

Handwash occasions at home and in school, before and after critical time-points, and thier association with diarrheal disease and RI outcomes in children, determined by multivariate logistic regression models, are reported in Tables 4 and 5 respectively. The prevalence of handwashing at key occasions at home is shown in Supplementary Figure S1. Handwashing before preparing and after preparing food (practiced by $\sim 24 \%$ and $\sim 20 \%$ respectively) significantly reduced the odds of both diarrheal disease and RI by $50 \%$ to $70 \%$. Handwashing after defecation was also significantly protective against diarrhea and RI. However, only $34.2 \%$ of the children said they washed hands after defecation. Handwashing after cleaning dishes by hand (practiced by $16.5 \%$ ) was associated with $85 \%$ and $61 \%$ lowered odds of diarrhea and RI respectively. At school, handwashing after playing reduced the odds of diarrhea by $57 \%$ and of RI by $74 \%$. Nearly $20 \%$ of the children reported they washed hands after playing in school. Washing hands after using the toilet increased RI incidence. In addition, handwashing prevalence after eating at home or in school was significantly higher in girls than boys ( $p<0.01$ for both). Around $90 \%$ of the girls said they washed hands after eating both at home and in school while $84 \%$ of the boys said they washed hands after eating at home and only $64 \%$ of the boys reported handwashing after eating in school. For participants who reported incidence of diarrheal disease, frequency of handwashing at critical time points ranged from $4.7 \% \%$ to $88 \%$ across the range of occasions described in Table 4 . For those who reported RI incidence, frequency of handwashing at critical time points ranged from $6.9 \%$ to $89.2 \%$ for the different occasions (Table 5).

\subsection{Timing of Handwash Activities and Infectious Disease Outcomes}

The mothers' beliefs regarding the benefits of handwashing are shown in Figure 1. A little more than half of the participating mothers (i.e., $57.2 \%$ ) believed that handwashing would prevent diarrhea and RI in their children. Almost a quarter of the mothers $(24.4 \%)$ interviewed were skeptical about the benefits of handwashing, while $18.4 \%$ did not believe that handwashing was effective against diarrhea and RI.

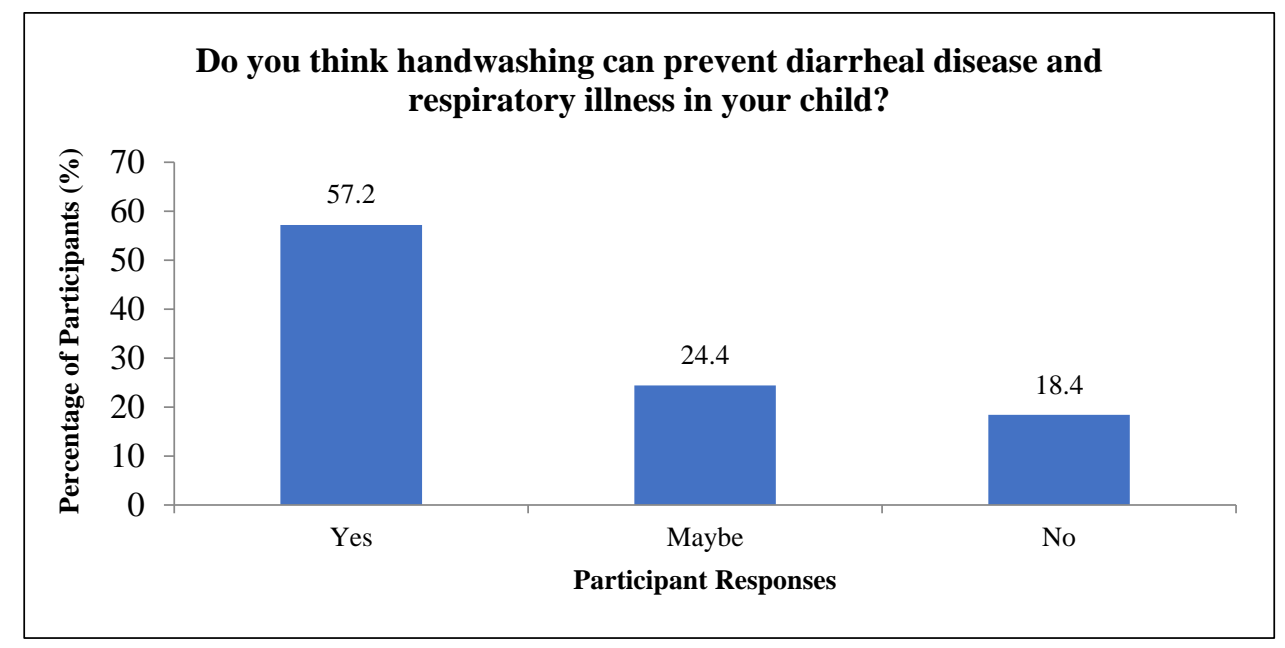

Figure 1. Participant responses for perception of diarrheal and respiratory illness prevention from handwashing. 
Table 4. Unadjusted and adjusted odds ratios for association between handwashing at critical time points and diarrheal disease outcome.

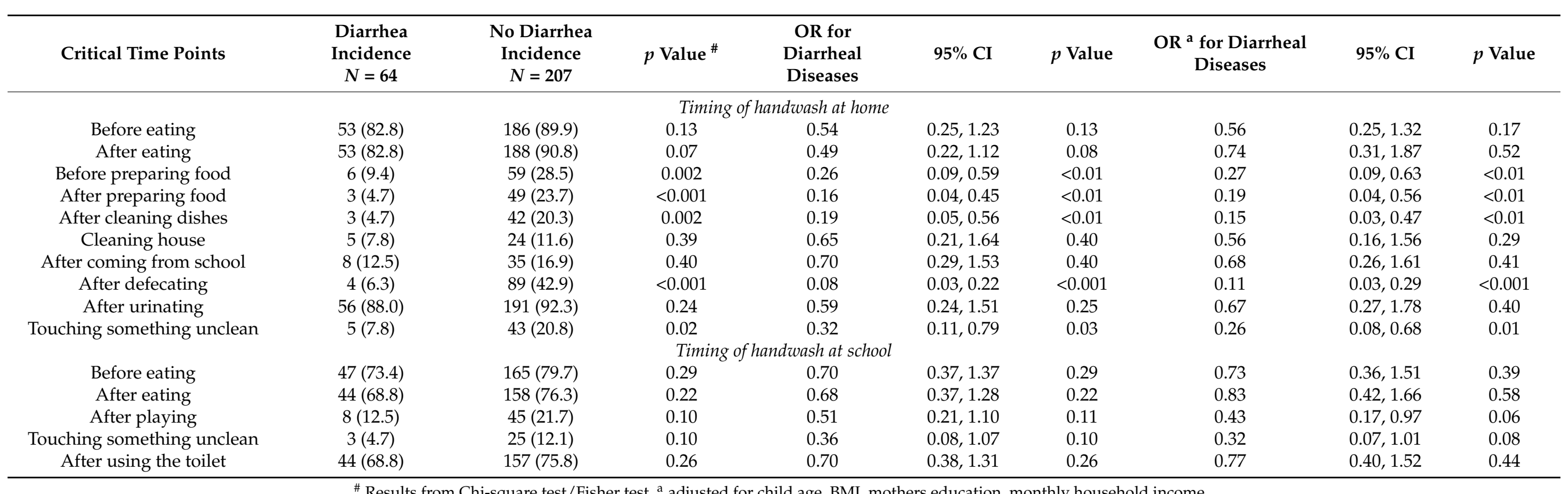

" Results from Chi-square test/Fisher test, ${ }^{\text {a }}$ adjusted for child age, BMI, mothers education, monthly household income. 
Table 5. Unadjusted and adjusted odds ratios for association between handwashing at critical time points and respiratory illness outcome.

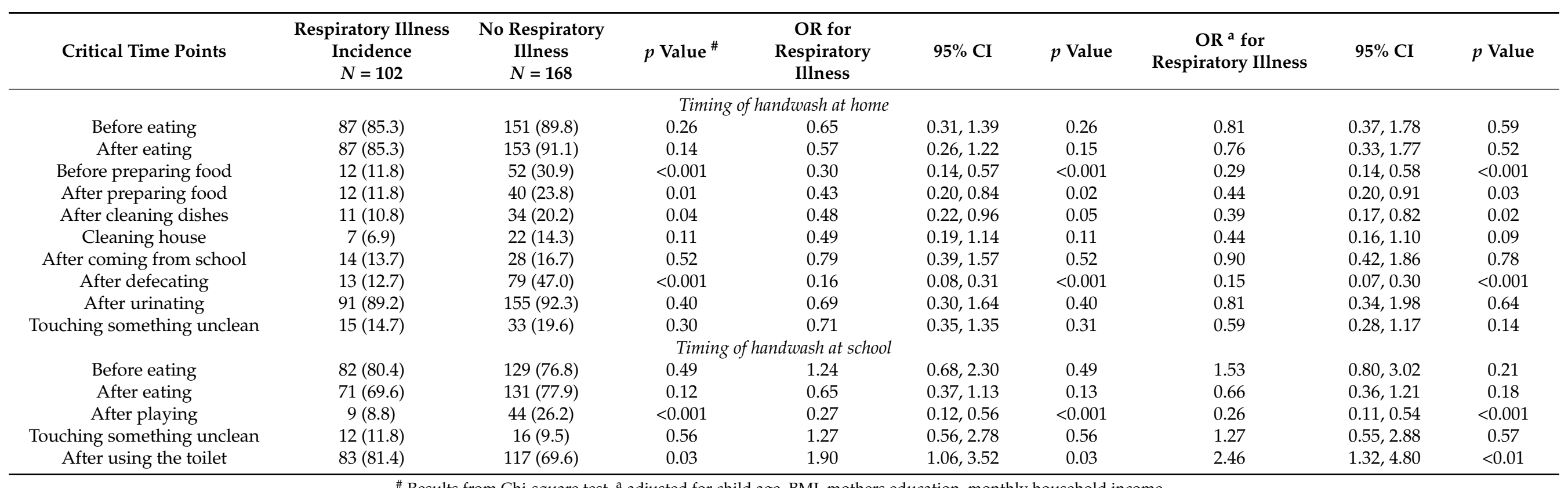

\# Results from Chi-square test, ${ }^{\text {a }}$ adjusted for child age, BMI, mothers education, monthly household income. 


\section{Discussion}

We report an association between improved handwashing behavior at critical timepoints and a reduction of the mother-reported incidence of diarrheal disease and RI in children. Our results are consistent with several other studies conducted elsewhere, which have identified regular hand hygiene practice as an effective barrier against these two diseases $[15,16,23,36]$. We have reported some critical time-points of handwashing that are linked to reduced odds of both diarrhea and RI such as before and after food preparations, after defecation, and after dish cleaning by hands. We observe similar findings in other parts of the world among people with low socioeconomic status. Studies conducted in Bangladesh and Ethiopia also found that washing hands before food preparation and after defecation as most important for prevention of diarrhea in children in urban slums $[37,38]$. Additionally, we found a low prevalence of handwashing at these critical time-points. Similar to our findings, another study in India [21] reported less than $30 \%$ of mothers and schoolchildren were handwashing with soap on key occasions, both at baseline and at follow-up.

Even though handwashing with soap is the recommended practice, we found that using a bar soap or a liquid soap was not associated with diarrheal or RI incidence. Similar to our results, two prior studies reported that handwashing with a bar soap was not associated with influenza [39,40] and diarrhea [40]. This might be due to inadequate frequency of handwashing observed in our sample [39]. We identified the use of a clean cloth to dry hands post-handwashing to be significantly protective against diarrheal disease and RI. This is consistent with current handwashing guidelines that recommend using a clean towel to dry hands [41]. Unexpectedly, RI incidence increased when children reported handwashing after using the toilet in school. This may be explained due to inadequate soap use or crowded school toilets leading to improper handwashing practice. Respiratory illness incidence in Delhi is also high due to severe air pollution throughout the year, which may have biased our results.

As expected, we found that forgetting to wash hands was a statistically significant risk factor of diarrhea. This finding is similar to a study in Colombia [42], where forgetting to wash hands was the most commonly reported barrier of personal hygiene promotion. A tub of water with a mug outside the house is a common handwash station in low-income communities in India. Nevertheless, it represents an unhygienic facility that is vulnerable to contamination. We also found that such an infrastructure was significantly associated with increased odds of diarrheal disease incidence, but not with RI. Contrary to our finding, presence of a handwashing station with both soap and water showed no association with diarrhea prevalence, but increased RI prevalence in Kenya, which may have occurred due to unmeasured confounding [40].

Just over half of our study participants (57.2\%) believed that handwashing would help in reducing diarrheal diseases or RI. The poor perception and low confidence for the benefits of handwashing among adult females underscores the need for handwashing awareness and intervention programs targeting mothers and children from low-income households in India. A study in Pakistan found that a majority of adult respondents believed overeating to be the most important risk factor of diarrhea. While contaminated food and water were also believed to be causal factors; the participants referred to flies or visible dirt, rather than microscopic bacteria and germs, as the major risk factors for hand contamination and infection transmission [43]. Similarly, a study in Bangladesh reported only a small percentage of the informants believed that handwashing was helpful in reducing RI. The majority believed that keeping a safe distance from the infected individual could be the most effective strategy to prevent RI. In addition, the participants did not think it was always feasible to wash hands after coughing or sneezing [44]. All of these findings indicate that cultural belief regarding the appropriate timing of handwash remains a barrier of sustainable hand hygiene promotion. Future studies can also investigate if mother's handwashing beliefs impact their children's attitude towards handwashing and handwashing practices. 
There were some potential limitations in our study. Most results are based on parentreported data and no direct observation of handwashing behavior was included in the study design. This may have led to recall bias and over-reporting of handwashing due to social desirability bias. Incidence of diarrheal and RI infection was also parent-reported. We acknowledge that our outcome data may also be subject to recall bias. There may be over-reporting, under-reporting and misclassification of diarrheal disease and RI incidence in our sample. However, we asked detailed questions in order to capture the most accurate answers regarding these experiences. It is plausible that the mothers may have had difficulty in remembering the frequency of our outcomes in the past year for their children. To address some of this concern, our outcome was analysed as a dichotomous variable with a "yes" or "no" response to any incidence of the outcome in the past year.

Our study does not report any microbiological data identifying potential pathogens that may have caused diarrhea and RI in the children. Microorganisms cause the most severe outbreaks of diarrhea and RI. Living in crowded areas with poor hygiene and sanitation conditions facilitate easy transmission of microbes. Co-infection with more than one microorganism is also common, causing more serious cases of diarrhea and RI [6]. In our future studies we will incorporate microbial data analysed from samples collected from households and children's hands. Because this is a cross-sectional study, temporality cannot be established. However, it is well known that poor hand hygiene leads to diarrheal disease and RI. In addition, this study represents handwash behavior in a small subset of the Indian population. Whether the findings are generalizable across other rural and urban populations in India and other LMICs remain unclear. Additionally, there may be confounding by variables that were not measured in this study.

\section{Conclusions}

In our study, we have reported that safe handwashing practices at critical times can reduce the parent-reported risk of diarrhea and RI. Despite being a low-cost prevention measure, we found low prevalence of handwashing at important time-points, and only around $60 \%$ of participants believed in its effectiveness. Forgetfulness was observed to be the biggest barrier to handwashing. These study findings will inform our ongoing handwash behavioral change intervention. Based on our results, we recommend future studies focus on understanding what facilitates handwashing such as having an accessible handwashing station, sufficient clean water supply and easy availability of soap while addressing the hindrances, such as forgetfulness and cultural beliefs, with appropriate cues and education to promote improved handwashing behavior by vulnerable mother and child populations.

Supplementary Materials: The following is available online at https://www.mdpi.com/article/10.3 390/ijerph182312535/s1. Figure S1. Prevalence of self-reported handwashing at different time points at home.

Author Contributions: Conceptualization: K.M.K. and B.S.; methodology: K.M.K., R.C., R.S. and P.U.; formal analysis: R.C. and A.C.; writing—original draft preparation: K.M.K., R.C., S.B., R.S. and A.C.; writing-review and editing: K.M.K., R.C., S.B., R.S., D.T. and B.S.; funding acquisition: K.M.K.; supervision: K.M.K., B.S., K.M.K. and R.C. contributed equally (as joint first-author) to this work. All authors have read and agreed to the published version of the manuscript.

Funding: This research was funded by President's International Research Award (PIRA), an internal grant from Indiana University Bloomington, Indiana and the APC was funded by Sam Houston State University, Huntsville, TX, USA.

Institutional Review Board Statement: The study was conducted according to the guidelines of the Declaration of Helsinki, and approved by the Institutional Review Board (or Ethics Committee) of Indiana University Bloomington (Protocol \# 1805321556; date of approval: 28 August 2018) and Amity University Uttar Pradesh.

Informed Consent Statement: Verbal informed consent and assent was obtained from all mothers and children involved in the study. 
Data Availability Statement: The dataset analysed during the current study are available from the corresponding author on reasonable request.

Acknowledgments: We wish to thank Naveen Shukla and all the RAs and staff from SEEDS who helped in organizing and recruiting the participants and conducting the extensive field interviews.

Conflicts of Interest: The authors declare no conflict of interest. The funders had no role in the design of the study; in the collection, analyses, or interpretation of data; in the writing of the manuscript, or in the decision to publish the results.

\section{References}

1. Walker, C.L.F.; Rudan, I.; Liu, L.; Nair, H.; Theodoratou, E.; Bhutta, Z.A.; O’Brien, K.L.; Campbell, H.; Black, R.E. Global burden of childhood pneumonia and diarrhoea. Lancet 2013, 381, 1405-1416. [CrossRef]

2. Wang, H.; Naghavi, M.; Allen, C.; Barber, R.M.; Bhutta, Z.A.; Carter, A.; Casey, D.C.; Charlson, F.J.; Chen, A.Z.; Coates, M.M. Global, regional, and national life expectancy, all-cause mortality, and cause-specific mortality for 249 causes of death, 1980-2015: A systematic analysis for the Global Burden of Disease Study 2015. Lancet 2016, 388, 1459-1544. [CrossRef]

3. Murray, C.J.; Vos, T.; Lozano, R.; Naghavi, M.; Flaxman, A.D.; Michaud, C.; Ezzati, M.; Shibuya, K.; Salomon, J.A.; Abdalla, S.; et al. Disability-adjusted life years (DALYs) for 291 diseases and injuries in 21 regions, 1990-2010: A systematic analysis for the Global Burden of Disease Study 2010. Lancet 2012, 380, 2197-2223. [CrossRef]

4. WHO. Global Sealth Estimates 2016: Disease Burden by Cause, Age, Sex, by Country and by Region, 2000-2016; World Health Organization: Geneva, Switzerland, 2018.

5. Uppal, B.; Perween, N.; Aggarwal, P.; Kumar, S.K. A comparative study of bacterial and parasitic intestinal infections in India. J. Clin. Diagn. Res. 2015, 9, DC01-DC4. [CrossRef]

6. Shrivastava, A.K.; Kumar, S.; Mohakud, N.K.; Suar, M.; Sahu, P.S. Multiple etiologies of infectious diarrhea and concurrent infections in a pediatric outpatient-based screening study in Odisha, India. Gut Pathog. 2017, 9, 16. [CrossRef]

7. Bhuyan, G.S.; Hossain, M.A.; Sarker, S.K.; Rahat, A.; Islam, M.T.; Haque, T.N.; Begum, N.; Qadri, S.K.; Muraduzzaman, A.K.M.; Islam, N.N.; et al. Bacterial and viral pathogen spectra of acute respiratory infections in under-5 children in hospital settings in Dhaka city. PLoS ONE 2017, 12, e0174488. [CrossRef]

8. Khan, S.; Priti, S.; Ankit, S. Bacteria etiological agents causing lower respiratory tract infections and their resistance patterns. Iran. Biomed. J. 2015, 19, 240-246. [CrossRef] [PubMed]

9. Malhotra, B.; Swamy, M.A.; Janardhan Reddy, P.V.; Gupta, M.L. Viruses causing severe acute respiratory infections (SARI) in children $\leq 5$ years of age at a tertiary care hospital in Rajasthan, India. Ind. J. Med. Res. 2016, 144, 877-885. [CrossRef] [PubMed]

10. Prüss-Ustün, A.; Bartram, J.; Clasen, T.; Colford, J.M., Jr.; Cumming, O.; Curtis, V.; Bonjour, S.; Dangour, A.D.; De France, J.; Fewtrell, L.; et al. Burden of disease from inadequate water, sanitation and hygiene in low-and middle-income settings: A retrospective analysis of data from 145 countries. Trop. Med. Int. Health 2014, 19, 894-905. [CrossRef]

11. Pinkerton, R.; Oriá, R.B.; Lima, A.A.; Rogawski, E.T.; Oriá, M.O.; Patrick, P.D.; Moore, S.R.; Wiseman, B.L.; Niehaus, M.D.; Guerrant, R.L. Early childhood diarrhea predicts cognitive delays in later childhood independently of malnutrition. Am. J. Trop. Med. Hyg. 2016, 95, 1004-1010. [CrossRef]

12. Checkley, W.; Buckley, G.; Gilman, R.H.; Assis, A.M.; Guerrant, R.L.; Morris, S.S.; Mølbak, K.; Valentiner-Branth, P.; Lanata, C.F.; Black, R.E. Multi-country analysis of the effects of diarrhoea on childhood stunting. Int. J. Epidemiol. 2008, 37, 816-830. [CrossRef]

13. Bussières, A.; Hartvigsen, J.; Ferreira, M.L.; Ferreira, P.H.; Hancock, M.J.; Stone, L.S.; Wideman, T.H.; Boruff, J.; Elklit, A. Adverse childhood experience and adult persistent pain and disability: Protocol for a systematic review and meta-analysis. Syst. Rev. 2020, 9, 1-9. [CrossRef]

14. Giovanelli, A.; Reynolds, A.J.; Mondi, C.F.; Ou, S.-R. Adverse childhood experiences and adult well-being in a low-income, urban cohort. Pediatrics 2016, 137, 10. [CrossRef]

15. Aiello, A.E.; Coulborn, R.M.; Perez, V.; Larson, E.L. Effect of hand hygiene on infectious disease risk in the community setting: A meta-analysis. Am. J. Public Health 2008, 98, 1372-1381. [CrossRef] [PubMed]

16. Ejemot-Nwadiaro, R.I.; Ehiri, J.E.; Arikpo, D.; Meremikwu, M.M.; Critchley, J.A. Hand washing promotion for preventing diarrhoea. Cochrane Database Syst. Rev. 2015, 2015, Cd004265. [CrossRef] [PubMed]

17. Luby, S.P.; Agboatwalla, M.; Feikin, D.R.; Painter, J.; Billhimer, W.; Altaf, A.; Hoekstra, R.M. Effect of handwashing on child health: A randomised controlled trial. Lancet 2005, 366, 225-233. [CrossRef]

18. Curtis, V.; Cairncross, S. Effect of washing hands with soap on diarrhoea risk in the community: A systematic review. Lancet Infect. Dis. 2003, 3, 275-281. [CrossRef]

19. Rabie, T.; Curtis, V. Handwashing and risk of respiratory infections: A quantitative systematic review. Trop. Med. Int. Health 2006, 11, 258-267. [CrossRef] [PubMed]

20. Freeman, M.C.; Stocks, M.E.; Cumming, O.; Jeandron, A.; Higgins, J.P.; Wolf, J.; Prüss-Ustün, A.; Bonjour, S.; Hunter, P.R.; Fewtrell, L.; et al. Hygiene and health: Systematic review of handwashing practices worldwide and update of health effects. Trop. Med. Int. Health 2014, 19, 906-916. [CrossRef] 
21. Biran, A.; Schmidt, W.P.; Wright, R.; Jones, T.; Seshadri, M.; Isaac, P.; Nathan, N.A.; Hall, P.; McKenna, J.; Granger, S.; et al. The effect of a soap promotion and hygiene education campaign on handwashing behaviour in rural India: A cluster randomised trial. Trop. Med. Int. Health 2009, 14, 1303-1314. [CrossRef]

22. Townsend, J.; Greenland, K.; Curtis, V. Costs of diarrhoea and acute respiratory infection attributable to not handwashing: The cases of India and China. Trop. Med. Int. Health 2017, 22, 74-81. [CrossRef] [PubMed]

23. Mbakaya, B.C.; Lee, P.H.; Lee, R.L. Hand hygiene intervention strategies to reduce diarrhoea and respiratory infections among schoolchildren in developing countries: A systematic review. Int. J. Environ. Res. Public Health 2017, 14, 371. [CrossRef] [PubMed]

24. Talaat, M.; Afifi, S.; Dueger, E.; El-Ashry, N.; Marfin, A.; Kandeel, A.; Mohareb, E.; El-Sayed, N. Effects of hand hygiene campaigns on incidence of laboratory-confirmed influenza and absenteeism in schoolchildren, Cairo, Egypt. Emerg. Infect. Dis. 2011, 17, 619-625. [CrossRef]

25. Tidwell, J.B.; Gopalakrishnan, A.; Unni, A.; Sheth, E.; Daryanani, A.; Singh, S.; Sidibe, M. Impact of a teacher-led school handwashing program on children's handwashing with soap at school and home in Bihar, India. PLoS ONE 2020, 15, e0229655. [CrossRef] [PubMed]

26. Bresee, S.; Caruso, B.A.; Sales, J.; Lupele, J.; Freeman, M.C. 'A child is also a teacher': Exploring the potential for children as change agents in the context of a school-based WASH intervention in rural Eastern Zambia. Health Educ. Res. 2016, 31, 521-534. [CrossRef]

27. Nicholson, J.A.; Naeeni, M.; Hoptroff, M.; Matheson, J.R.; Roberts, A.J.; Taylor, D.; Sidibe, M.; Weir, A.J.; Damle, S.G.; Wright, R.L. An investigation of the effects of a hand washing intervention on health outcomes and school absence using a randomised trial in Indian urban communities. Trop. Med. Int. Health 2014, 19, 284-292. [CrossRef]

28. Hashi, A.; Kumie, A.; Gasana, J. Hand washing with soap and WASH educational intervention reduces under-five childhood diarrhoea incidence in Jigjiga District, Eastern Ethiopia: A community-based cluster randomized controlled trial. Prev. Med. Rep. 2017, 6, 361-368. [CrossRef] [PubMed]

29. Dey, N.C.; Parvez, M.; Islam, M.R.; Mistry, S.K.; Levine, D.I. Effectiveness of a community-based water, sanitation, and hygiene (WASH) intervention in reduction of diarrhoea among under-five children: Evidence from a repeated cross-sectional study (2007-2015) in rural Bangladesh. Int. J. Hyg. Environ. Health 2019, 222, 1098-1108. [CrossRef]

30. Morris, S.K.; Bassani, D.G.; Awasthi, S.; Kumar, R.; Shet, A.; Suraweera, W.; Jha, P. Diarrhea, pneumonia, and infectious disease mortality in children aged 5 to 14 years in India. PLoS ONE 2011, 6, e20119. [CrossRef]

31. Taddese, A.A.; Dagnew, B.; Dagne, H.; Andualem, Z. Mother's handwashing practices and health outcomes of under-five children in Northwest Ethiopia. Pediatric Health Med. Ther. 2020, 11, 101. [CrossRef]

32. Haruna, S.; Gobir, A.; Sambo, M.; Salaudeen, A. Effect of health education on hand washing of mothers of under five children on diarrhoea episodes in a Nigerian rural community. Trop. J. Health Sci. 2017, 24, 8-13.

33. Levine, G.A.; Walson, J.L.; Atlas, H.E.; Lamberti, L.M.; Pavlinac, P.B. Defining pediatric diarrhea in low-resource settings. J. Pediatric Infect. Dis. Soc. 2017, 6, 289-293. [CrossRef] [PubMed]

34. Macpherson, G. Black's Medical Dictionary; A\&C Black: London, UK, 2002.

35. de Onis, M.; Onyango, A.W.; Borghi, E.; Siyam, A.; Nishida, C.; Siekmann, J. Development of a WHO growth reference for school-aged children and adolescents. Bull. World Health Organ. 2007, 85, 660-667. [CrossRef]

36. Luby, S.P.; Agboatwalla, M.; Painter, J.; Altaf, A.; Billhimer, W.L.; Hoekstra, R.M. Effect of intensive handwashing promotion on childhood diarrhea in high-risk communities in Pakistan: A randomized controlled trial. JAMA 2004, 291, 2547-2554. [CrossRef]

37. Luby, S.P.; Halder, A.K.; Huda, T.; Unicomb, L.; Johnston, R.B. The effect of handwashing at recommended times with water alone and with soap on child diarrhea in rural Bangladesh: An observational study. PLoS Med. 2011, 8, e1001052. [CrossRef] [PubMed]

38. Adane, M.; Mengistie, B.; Mulat, W.; Medhin, G.; Kloos, H. The most important recommended times of hand washing with soap and water in preventing the occurrence of acute diarrhea among children under five years of age in Slums of Addis Ababa, Ethiopia. J. Community Health 2018, 43, 400-405. [CrossRef]

39. Doshi, S.; Silk, B.J.; Dutt, D.; Ahmed, M.; Cohen, A.L.; Taylor, T.H.; Brooks, W.A.; Goswami, D.; Luby, S.P.; Fry, A.M. Householdlevel risk factors for influenza among young children in Dhaka, Bangladesh: A case-control study. Trop. Med. Int. Health 2015, 20, 719-729. [CrossRef] [PubMed]

40. Kamm, K.B.; Feikin, D.R.; Bigogo, G.M.; Aol, G.; Audi, A.; Cohen, A.L.; Shah, M.M.; Yu, J.; Breiman, R.F.; Ram, P.K. Associations between presence of handwashing stations and soap in the home and diarrhoea and respiratory illness, in children less than five years old in rural western Kenya. Trop. Med. Int. Health 2014, 19, 398-406. [CrossRef]

41. PPPHW. Global Handwashing Day Planner's Guide. Available online: https://globalhandwashing.org/resources/globalhandwashing-day-planners-guide-2018/ (accessed on 30 July 2021).

42. Lopez-Quintero, C.; Freeman, P.; Neumark, Y. Hand washing among school children in Bogotá, Colombia. Am. J. Public Health 2009, 99, 94-101. [CrossRef]

43. Nielsen, M.; Hoogvorst, A.; Konradsen, F.; Mudasser, M.; van der Hoek, W. Causes of childhood diarrhea as perceived by mothers in the Punjab, Pakistan. Southeast Asian J. Trop. Med. Public Health 2003, 34, 343-351. [PubMed]

44. Nizame, F.A.; Nasreen, S.; Unicomb, L.; Southern, D.; Gurley, E.S.; Arman, S.; Kadir, M.A.; Azziz-Baumgartner, E.; Luby, S.P.; Winch, P.J. Understanding community perceptions, social norms and current practice related to respiratory infection in Bangladesh during 2009: A qualitative formative study. BMC Public Health 2011, 11, 901. [CrossRef] [PubMed] 